\title{
PARTICIPATION IN BOYS AND GIRLS CLUBS: MOTIVATION AND STAGE ENVIRONMENT FIT
}

\author{
Jennifer A. Fredricks and Kristen Hackett \\ Connecticut College
}

Allyson Bregman

University of Michigan

This article presents the results of semi-structured in-depth interviews conducted with 54 youth attending six elementary school-based and middle school-based Boys and Girls Clubs in two low-income communities. The first goal of this study was to examine why youth choose to participate in these clubs. The most commonly reported motives include fun activities, opportunities to be with friends, parent has to work, and getting help with homework. The second goal was to examine youths' perceptions of staff, peers, activities, and the extent to which clubs are organized in a way to support the need for relatedness, competence, and autonomy. Variations in youth' perceptions of the quality of relationships with staff and peers, level of interest and challenge, and opportunities for decision making, by developmental level (elementary versus middle school) are discussed. Implications of our findings for sustaining youths' interest and continued involvement in out-of-school youth development programs are highlighted. (C) 2010 Wiley Periodicals, Inc.

There is a growing recognition that school-based and community-based after-school programs represent an important context for positive youth development and that involvement may be especially important for children living in high-risk and

\footnotetext{
The authors would like to acknowledge the Holleran Center for Community Action and Public Policy at Connecticut College who provided support for this project. Portions of these findings were presented at the Society for Research in Adolescence Annual Meeting in Chicago, 2008. We would like to thank Cheryl Jacobs and Nicole Porter for their assistance with data collection. We would also like to thank the staff and executive director for their assistance with data collection.

Correspondence to: Jennifer A. Fredricks, Connecticut College, Box 5223, New London, CT 06320.

E-mail: jfred@conncoll.edu
} 
low-income neighborhoods (Eccles \& Gootman, 2002; Mahoney, Larson, \& Eccles, 2005). Low-income youth are at risk for poorer academic, social, and psychological outcomes and are more likely to live in communities where there are fewer structured after-school contexts and a heightened presence of neighborhood risks (Gephart, 1997; Halpern, 1999). Organized out-of-school activities share several features that are linked to positive youth development, including supervision and guidance by nonfamilial adults, links to prosocial peers, opportunities to develop particular skills and competencies, and opportunities for meaningful autonomous participation (Eccles \& Gootman, 2002; Mahoney et al., 2005). Participation in school-based and communitybased after-school programs is associated with a variety of positive developmental outcomes, including higher motivation and academic performance, lower incidence of problem behavior, enhanced social competence, and improved mental health, though the number of well-designed and methodologically rigorous studies is limited (Catalano et al., 1999; Eccles \& Gootman, 2002; Feldman \& Matjasko, 2005).

\section{Boys and Girls Clubs}

Boys and Girls Clubs of America (BGCAS) is one of the oldest and leading communitybased youth development organizations, currently serving over 4.5 million youth at over 4,300 clubs nationwide. (see http:/www.bgca.org). The mission of these clubs is to provide a positive and safe place for youth, where they can be supervised and supported by caring adults, with the goal of helping them to reach their full potential as productive, caring, and responsive citizens (Aberton, Sheldon, \& Herrera, 2005). BGCAS offers programs in five core areas: character and leadership development; education and career development; health and life skills; the arts; and sport, fitness, and recreation.

Hirsch and his colleagues have conducted the most comprehensive research on youths' experience in Boys' and Girls' Clubs (Hirsch, 2005; Hirsch et al., 2000; Loder \& Hirsch, 2003; Roffman, Pagano, \& Hirsch, 2001). They used ethnographic data, surveys, and structured interviews to describe how urban African American and Hispanic youth often see these clubs as a second home and how these settings are a powerful context for developing close and supportive relationships with adults and peers. In a qualitative study of the outcomes of youths' involvement in BGCAS, Carruthers and Busser (2000) found that the majority of youth thought that the club provided a nurturing and family like environment, helped them acquire prosocial behaviors, and increased their perceptions of competence and self-esteem. Finally, there have been a few evaluations of the consequences of participating in discrete prevention programs at the BGCAS on a range of developmental outcomes. Evidence from this research shows that participation in these programs is linked to a reduction in delinquent behavior, higher academic achievement, and improved attitudes toward school (Marzke, Hidreth, \& Smith, 2001; St. Pierre, Mark, Kaltreider, \& Aikin, 1997; Schinke, Orlandi, \& Cole, 1992).

Although this research highlights the potential developmental benefits of participating in youth development programs like the BGCAS, there are several questions that remain. Few studies have examined the diverse range of developmental experiences youth are exposed in these settings (Aberton, Sheldon, \& Herrera, 2005). In addition, we know less about participation and youths' experience in typical rather than exemplar community-based programs (Anderson-Butcher, Newsome, \& Ferrari, 2003; Halpern, Barker, \& Mollard, 2000). This is an important gap because "typical" or "garden variety" programs usually operate with greater constraints on funding, 
space, and staff, factors likely to impact on the experience of youth (Halpern et al., 2000). Moreover, because of the potential developmental benefits of involvement, it is also important to understand why youth initially come to these programs, why they choose to stay, and why they dropout. In general, participation in community-based organizations declines as children move into adolescence (Eccles \& Gootman, 2002). Getting youth to attend and stay engaged is one of the biggest challenges facing youth development programs, though there is very little empirical research to guide practitioners on this issue (Eccles, 2005; Weiss, Little, \& Bouffard, 2005). Our article addresses these gaps in the literature.

\section{Motivation and Participation in Out-of-School Activities}

Research on community-based organizations. A handful of studies have explored why youth choose to participate in community-based programs. Hirsch (2005) found that parents, peers, and activities were the most common reasons why youth initially came to the clubs, and friendships were the biggest reason they continued to attend. Halpern and Colleagues (2000) asked 24 youth attending five neighborhood youth programs in a lowincome Latino neighborhood in Chicago why they came and why they stayed at the center. The two most frequently mentioned reasons why they came were that the program was a physically and psychologically safe place to hang out with friends and that youth valued their relationships with program staff. Finally, Perkins and colleagues (Borden, Perkins, Villarruel, \& Stone, 2005; Perkins et al., 2007) examined why ethnic minority urban youth choose to attend structured youth programs. Youth talked about how participation in these programs keeps them off the streets, helps them learn new things, helps them to avoid boredom, and allows them to participate in enjoyable activities. These youth also gave a variety of reasons why they did not participate such as lack of time, other interests, negative opinions of the youth center, and parental restrictions.

Research on extracurricular activities. There is also a literature on motivation and participation in extracurricular activities that can provide some insight into why youth participate and dropout of community-based organizations. Much of this research has focused on motivation and sports participation. Competence and enjoyment are common motives for sports participation (Weiss \& Petlichkoff, 1989; Weiss \& Williams, 2004). Factors such as too much pressure, the desire to pursue other interests, lack of competence, and lack of enjoyment are also related to the decision to dropout of sports. (See Brustad, Babkes, \& Smith, 2001, for review.) Qualitative research with highly involved youth in athletics and the arts indicates that another reason why youth both join and stay in organized activities is the opportunity to spent time with their friends and/or to meet new friends (Fredricks et al., 2002; Patrick et al., 1999). Finally, parents play a role in youths' decision to participate in organized out-of-school activities (Huebner \& Mancini, 2003; Hultzman, 1993). Parents' modeling of an activity and parents' beliefs about the importance of involvement are associated with participation in out-of-school activities (Fletcher, Elder, \& Mekos, 2000; Fredricks \& Eccles, 2004). The decline in attendance in organized programs in adolescence may also be partly explained by the increased independence and choices parents give to older youth (Guavain \& Perez, 2005).

Other theories of motivation. Self-determination theory is another theoretical perspective they may provide insight into why youth initially become involved and 
choose to stay or leave out-of-school settings. According to self-determination theory (Ryan \& Deci, 2000), individuals should be motivated to become involved in contexts where the need for relatedness, autonomy, and competence are met. First, individuals have a basic need to be connected or related to others (i.e., relatedness). Second, individuals have a basic need to experience behavior as self-determined rather than guided by external incentives (i.e., autonomy). Finally, individuals have a need to demonstrate their ability in a context that interests them (i.e., competence). Elements of out-of-school settings that are thought to increase participation and support the need for relatedness, autonomy, and competence are adult leaders who are responsive and supportive, opportunities to develop relationships with peers, challenging and interesting tasks, and opportunities to be involved in decision making (AndersonButcher, 2005; Lauver \& Little, 2005; Weiss et al., 2005). Meeting these three needs may be especially important during early adolescence, a period characterized by increases in the desire for autonomy, peer orientation, salience of identity, and capacity for abstract thought (Eccles et al., 1993). One reason why adolescents may leave organized activities is the failure of these programs to meet these developmental needs, though few studies have tested this hypothesis (Eccles, 2005). One exception is research by McLaughlin (1999); exemplar community-based programs that have been successful at retaining adolescents offer opportunities for youth to be involved in decision making, assume leadership roles, and contribute to their community.

\section{Purpose}

In this article, we present findings from in-depth interviews with 54 youth attending three elementary school-based and three middle school-based BGCAS in two lowincome communities. Specifically, we address the following questions: (a) What are elementary and middle school youths' reasons for initially coming to the club? (b) Why do they choose not to attend the club? (c) What are youths' perceptions of staff, peers, and activities? (d) Are elementary and middle school clubs organized in a way to support the need for relatedness, competence, and autonomy? (e) Are there differences in how elementary and middle school clubs support these three needs?

\section{METHOD}

\section{Participants}

The sample includes 54 youth in fourth to eight grades [32 boys (59\%), 22 girls (41\%)] attending three elementary school-based $[N=27$ (11, 9, and 7 youth per club)] and three middle school-based BGCSAS $[N=27$ (14, 11 , and 2 youth per club)] in two small low-income cities in Southeastern Connecticut during the 2006 and 2007 school year. The numbers varied across clubs because of differences in the size of clubs, the stability of attendance over the course of the year, and how successful we were at obtaining parental consent. The elementary school clubs served 1st to 5th grade youth and the middle school clubs served 6th to 8 th grade youth. The clubs are one of the few after school options for youth in these two communities and cost families only $\$ 5.00$ per year to attend.

Our participants varied in both the duration ( 1 month or less to 6 years or more) and frequency of involvement (not at all last month to every day for several hours). 
Our sample is ethnically diverse [19 whites (35.2\%), 13 African American (29.1\%), 9 Latino (16.7\%), and 13 mixed race $(24.1 \%)]$. There was some variation in the demographic composition at each club. Two of the elementary school clubs served a higher percentage of minority youth (55\% of sample at each club), while the other elementary school club served a higher percentage of white youth $(57 \%$ of sample at that club). In addition, one of the middle school clubs served primarily minority youth (91\% of the sample). Our sample also includes a larger percentage of African American and Latino youth than the communities which the clubs serve.

We selected participants from all youth in the 4th to 8th grades who attended one of the six clubs and for whom we had obtained parental consent $(N=70)$. We spent three days during the fall of 2006 at each of the elementary school clubs where we talked with the parents of the 4th and 5th graders when they picked up their child about participating in the study. Since middle school youth did not have to be picked up by a parent, we mailed a description of the study and consent forms to all parents of youth at the club. We also mailed consent forms to parents of elementary school youth that we were not able to talk with at the club. Students who returned their consent form were given a $\$ 5.00$ McDonald Gift Certificate for participating in the study.

\section{Measures}

We conducted semi-structured interviews with each of the youth during the winter of 2007 who still attended the club $(N=54)$. These interviews included questions about participation, motivation, relationships with staff, relationships with peers, perceptions of activities, perceptions of the benefits of participation, time use within club and outside club, and comparisons of their experience at the club with their experiences at school. The interviews were conducted by one of five female members of the research team. Only the first author had a theoretical background in motivation and development. Each interviewee was trained on interviewing methods. We piloted the interviews to determine whether youth understood the questions and whether the questions and probes were effective in eliciting the quality and depth of responses we were seeking. Some questions were modified and additional probes were added to the final protocol based on these pilot interviews. Each interview was audio taped and transcribed and lasted between 30 minutes and 1 hour. In addition, parents filled out forms with basic demographic information. Finally, we collected daily attendance from each site.

\section{Analyses}

We used a combination of induction, deduction, and verification techniques to analyze the interviews. First, a member of the research team read each transcript and made a structured summary of the key issues for each individual. Next, we exchanged these summaries and discussed common themes that were emerging from the interviews. We then developed a list of codes from these themes and the literature on motivation and organized activity participation. We used NVivo, a qualitative analysis software package, to code the interviews (NVivo, 2008). As we coded, we made changes and additions to the coding framework based on additional themes that were emerging. The second author coded the majority of the interviews using NVivo. To check for consistency, the first author also coded a sample of interviews, and in general the two researchers agreed on the coding of the passages. 
In the next step we examined printed reports of the codes for the larger categories of motivation, time use outside the club, staff, peers, activities, autonomy, interest, and challenge, looking for commonalities and differences among youth. We also examined differences in these codes and frequency of themes at the elementary and middle school levels, across each of the six clubs, by gender, by ethnicity, and by length and frequency of participation (under 1 year as compared to over 3 years). In general, there were few systematic differences in findings across these groups.

\section{RESULTS}

\section{Why Do I Come?}

Elementary and middle school youth reported a variety of reasons why they initially chose to come to the clubs, often citing multiple motives for participating. The following quote from a white fourth-grade female illustrates this theme:

Interviewer: Why do you choose to come to the Boys and Girls Club?

Respondent: Because my friends are here and the Boys and Girls Club takes care of you while your parents are at work and it's fun.

Interviewer: Why did you choose to come to Boys and Girls Club rather than going to a different after-school program?

Respondent: Because all the other activities cost way more than the Boys and Girls Club.

Interviewer: If your mom has lots more money and could send you somewhere else, would you still want to come to the Boys and Girls Club?

Respondent: Yes. Because I feel, like, I'm part of a group here and I have a lot of friends here and I feel that I'm safe here.

The most commonly reported motive for both elementary and middle school youth was that club was fun and that they were bored or did not, like, being at home. When we probed about what made it fun, they gave several responses: (a) the activities, (b) playing outside and in the gym, (c) spending time with friends, (d) opportunities for choice, (e) snacks, (f) and a more relaxed atmosphere than at school. The following quotes illustrate the different aspects of club that youth perceived as fun:

Respondent: Because they have really fun activities, and we get to do cool crafts, and you get to say what you want to say, like, I want to do a certain activity you can say it to the staff and they would probably do it (Latino fifthgrade female).

Respondent: I decided to come because I knew that if I have problems I can talk to staff and I knew that I have a lot of fun here.

Interviewer: What's fun about it here? 
Respondent: What's fun about it is that we get to do group activities together, like, as a group.... That's fun because knowing that you have people around you that, like, to do things with you, kinda makes people feel good.... We play Monopoly, we play board games, we watch movies on Fridays. It's fun to do our homework; in case we need help we have them right there (white sixthgrade female).

Respondent: Why do you have more fun here?

Interviewer: Because, like you feel more free. You feel, like, you can do more different things instead of being locked in a classroom.... You just get crazy and listen to music (African American eight-grade female).

Social factors were the second most commonly cited motive. Many youth talked about coming because their friends attended the program, they were looking for ways to meet new peers, and they wanted to be part of a group. The following two quotes illustrate the importance of social factors:

Some kids here are people you haven't known yet, so like you get to know them, 'cause like in my regular day like at school ... I'm always busy with work. And at the Boys and Girls Club you are always making new friends. 'Cause like when new friends come you can make friends with them and like some people you just ... like some of your old friends are here like you be surprised by how many. (African American seventh-grade male).

All my friends come here. It's, like, fun to hang out. It's a time to talk and, like, cuz there's only, like, 45 minutes in the day I get to talk to my friends and that's, like, lunch and flex. (white seventh-grade male)

Another reason many of the youth gave for coming to the club was the opportunity to get help with homework. For example, an African American eighth-grade female talked about how her reasons for coming changed in middle school.

Interviewer: Are there different reasons you come now than why you came when you were in elementary school?

Respondent: Now I come mainly to get help with my homework.

Other reasons youth cited for coming to the club are as follows: (a) supportive staff, (b) staying out of trouble, (c) feeling safe, and (d) opportunities for decision making.

We found differences in the motives for participation in the elementary and middle school clubs. In elementary school, motivation was more likely to be related to external factors such as, my parent has to work, my mom signed me up, and my parent makes me go. Only two of the middle school youth talked about their parents work obligation as a reason that they came. In middle school, youth cited both internal and external motives such as it was fun, they liked being with their friends and meeting new people, and they got help with their homework. We also documented some gender differences in motives for participation. Males were more likely than females to talk about coming to the club to: (1) get help with homework, (2) stay out of trouble, 
and (3) because they were bored at home. In contrast, only females mentioned opportunities for decision making as a reason for coming to the club.

\section{Why Don't I Come?}

There were several reasons why youth reported not attending club. At the elementary school level, the most common reasons for not attending were that their parents did not have to work or they had other family obligations such as visiting relatives. At the middle school clubs, participation in other after-school activities, such as sports, drama, babysitting, and dance, and other family obligations, such as helping with siblings, were the most cited reasons for not attending club. Other reasons cited by both elementary and middle school youth for not attending were that staff and other kids were mean, it was boring, and they wanted to spend time with their friends who were not in the program. When asked what they would be doing after-school if they were not at club, we got a variety of responses. The most common activity was doing homework and just hanging out at home with their friends and family. Other common uses of the after-school time included watching television, playing video games, or playing with friends. Finally, a few students talked about doing chores or helping their family when they are at home. There were no differences in the reasons youth did not come by gender, ethnicity, and duration of participation.

\section{Relationships With Adults}

In general, both elementary and middle school youth had positive impressions of their relationships with adult staff, though there were variations in the perceptions of the quality of these relationships both within and across the clubs. The staff was ethnically diverse, most lived in the same communities as the youth, and some were even relatives of some of the participants. Many youth felt that the staff was caring and supportive and provided a nurturing environment. Some youth developed close relationships with adults at the clubs, and a few even talked about staff liked friends or family.

Interviewer: Tell me about the staff. What are they like?

Respondent: The staff, they're amazing! They're nice and helpful. They're funny. They make people feel good, like, if they're sad, they make them feel better.... If you have a problem, they'll sit they'll, like, take you aside and they'll talk to you and everything. (white sixth-grade female)

Interviewer: What are your relationships like with staff?

Respondent: We are, like, really good friends. We all like to hang out....They treat all kids the same because we are, like, from one big family. (white fifthgrade female)

They talked about how the staff liked to have fun, played games with them, and helped them with their homework. Several of the youth reported that they felt comfortable talking with the staff about school, their family, and other personal issues, though there was variations in their level of comfort depending on the gender of the staff and their level of experience. They tended to feel most comfortable talking with 
more experienced staff and/or staff of the same gender. For example, an African American eighth-grade female said the following about the staff:

Respondent: I feel comfortable talking to Ms. [staff] about anything.

Interviewer: What do you talk to her about?

Respondent: I tell her about problems in my life, what happens in school, stuff like that.

Interviewer: What kinds of problems?

Respondent: I talked to her, like, when my parents divorced.

In contrast, some of the youth felt that they had not developed good relationships with some staff and would rather talk with friends and family about issues at the club or personal concerns. A few youth even talked about how some of the staff were mean and yelled at some kids. This was a more common response among male youth. For example, an African American fifth-grade male said this about the staff:

Interviewer: What are some reasons why you don't come?

Respondent: The staff, sometimes they're mean.... Sometimes the staff is kind of rude. Like, say if you get in trouble, they don't let you explain yourself. And sometimes they yell at you for no reason.

We documented few differences in youths' description of staff depending on the youths' duration of involvement or ethnicity. There were also few differences in themes related to staff at the elementary and middle school clubs. At both levels, staff varied in their ability to connect with the young people. Several participants talked about how the quality of the relationships with staff varied depending on each staff's personality and the length of time they had worked at the club. One possible reason for differences in youths' impressions of their relationships with adults was staff turnover at some of the clubs.

\section{Relationships With Peers}

In general, both the elementary and middle school youth had favorable impressions of the peers. Many youth talked about how they appreciated the opportunity to interact with their peers in a smaller and more relaxed setting than school. For example, a fifth-grade Latino male said this about his friends at the club:

I am closer to my friends than at school. 'Cause in school, ... you can only have fun in recess and that's about it.

We found no differences in youths' perceptions of their relationships with peers by ethnicity or amount of time at the club. Almost all youth could identify at least one close friend at the club who helped and supported them. They talked about how their peers provided both academic and social support, by helping them with homework, helping them to stay out of trouble, encouraging them to do their best, and cheering them up when they felt down. The following responses to the question, "How do your 
friends help and support you?", illustrate some of the different ways peers at the club provide support.

They tell me what not to do like if we are going to do something bad or somebody tried to fight me, they would like try to calm me down or something so I don't get in trouble (African American sixth-grade male)

When I am feeling bored and sad they come around and fool around with me and I feel happy. (African American eight-grade male)

We do homework and stuff together. We play together and if someone is not being fair we stick up for each other (White fourth-grade female)

Although most individuals had positive impressions of their peers, three of the youth at the middle school clubs talked about the negative peer dynamics and the teasing and bullying that occurred in these settings. For example, a white seventhgrade female said the following about her peers:

Respondent: There's some kids here who are just mean and they're kinda like bullies to all the people at the Boys and Girls Club.... Sometime the older kids like the eighth-graders they swear or they bully you, you know. Like, they'll say "your stupid" or they'll threaten you.

Interviewer: Do you have close friends here?

Respondent: I have one close friend.... If someone's picking on me, then she'll tell them to stop, like, that's not nice. And she'll tell them that she's not the only one that has something wrong with her or whatever. Like, 'cause I'm not good at math and people pick on me for that, so she'll tell them that I'm not the only one who's not good at something. And then she'll help me on my homework and I'll help her, if she needs it.

In addition, although most youth had friends at the club, a few individuals expressed disappointment about how many of the friends either did not attend club or had stopped coming to the program altogether.

\section{Tasks: Challenge and Interest}

Both elementary and middle school youth had varied impressions of the tasks. Most youth thought the activities were fun and interesting, though they differed in which aspects they most enjoyed. Youth talked about a variety of activities they enjoyed at club, including playing dodge ball, going outside, arts, homework, activities they did not usually get to do, board games, and other activities during free time. There also were developmental differences in which aspects of the club youth most enjoyed. The elementary school students reported more favorable impressions of the structured activities, while the middle school youth were more likely to report that they enjoyed playing pool, free time, hanging out with friends, and doing homework. In addition, males and females mentioned different activities they enjoyed doing at the club. Males were more likely to say that their favorite activity was playing pool and/or 
playing sports. Females were more likely to prefer doing group games and activities than were males.

Although most youth enjoyed the activities, some expressed concerns about the lack of variety and flexibility in scheduling. Some individuals thought too much time was spent on homework and academic preparation and reading. They also talked about how they wished it was not the first activity at club and that they could talk or do other activities besides reading a book if they finished their homework early. In addition, very few youth at either the elementary or the middle school clubs thought that the activities were challenging, though they did think they were interesting. For example, a mixed-race sixth-grade male said about the tasks:

Interviewer: Do you think the activities are challenging?

Respondent: No, it's pretty much easy. I haven't really experienced anything really hard yet.

In addition, a few of the elementary school youth talked about how they felt they had outgrown some of the activities for younger children.

Interviewer: What are your least favorite things to do at the club?

Respondent: Well sometimes we do games for little kids, which older kids don't really like and I don't really like now because I am older now. We do duck-duck goose for the little kids, or we do a game that is really fun because of the way it is played. (Latino fifth-grader)

\section{Opportunities for Decision Making}

Most youth at both the elementary and the middle school level felt they had some opportunities for decision making, though there were differences in the way the program encouraged autonomy at the two levels. In elementary school, youth had opportunities to make choices during free time and had club choice once a week in which they could choose among a variety of activities. All other activities at the elementary school were staff directed. For example, a mixed race fifth-grade girl described how club choice worked:

We do club every Wednesday and we get to pick what club we want to go to. There's music, art, dance club, and sports clubs.

At the middle school, youth talked about having opportunities to help plan the calendar, vote on activities, and make choices about how to spend their time during free and gym time. The following two quotes illustrate some different ways middle school youth can express autonomy.

Interviewer: Do you get to choose what kinds of activities you get to do at club?

Respondent: Yes, we always vote on everything. Like she says if we would rather go outside or go in the gym or something like that and everybody raises their hands and the most votes wins. (African American eighth-grade female) 
Interviewer: Do you have a say in the types of activities you do at the club?

Respondent: Most of the time, when we're choosing the games sometimes they just tell us we get the pool table or sometimes they just pick the games, but most of the time we go up there and we ask them what game are we going to play today and they say we have to decide because we're the one's playing it (African American 7th grade male)

Although staff still had a large say in activities and structure of program, the middle school youth talked about more opportunities for autonomy than did the elementary school youth.

\section{CONCLUSION}

Getting youth initially in the door and encouraging their continued involvement is one of the biggest challenges facing youth development programs. There is little empirical research to guide recruitment and retention efforts, which becomes increasing difficult as youth get older and have more choices about how to spend their discretionary time (Anderson-Butcher, 2005; Weiss et al., 2005). The first goal of our study was to explore the reasons why elementary and middle school youth chose to initially attend or not attend school-based BGCAS. Most youth reported multiple reasons why they attended the clubs, and males and females reported somewhat different reasons, suggesting that practitioners will need to use a variety of recruitment strategies to encourage involvement from both genders.

Consistent with prior research in both the youth development and the sport psychology literature, common motives for participation included fun activities, friends, safe environment, and supportive staff (Borden et al., 2005; Halpern et al., 2000; Hirsch, 2005; Weiss \& Williams, 2004). Evaluations of community-based organizations have also illustrated the importance of developing quality relationships with staff and having peers who attend the program in both initial participation and retention (Vandell et al., 2004; Walker \& Arbreton, 2004). Other reasons why youth come to these programs include getting help with homework, having the opportunities to make choices, and the relaxed atmosphere of clubs. These clubs did appear to represent an alternative space from schools and the streets, where youth felt safe and free to express themselves (Halpern, 2000). In addition, we documented differences in motives at the elementary and middle school clubs. In elementary school, the most common reason youth reported coming is that their parent needed to work and they could not be home alone. This finding suggests that these clubs may serve different purposes at the elementary and middle school levels, with childcare being a stronger focus of the programs for younger children and youth development a more prominent goal of the clubs serving older youth.

Reviews of high-quality youth programs have found that participation is associated with academic achievement, improved mental health, lower risk behaviors, and enhanced social competence (Catalano et al., 1999; Eccles \& Gootman, 2002). However, youth will not realize these benefits of participation if they do not attend on a regular basis. Consistent attendance is less characteristic of middle school programs than those serving younger youth (U.S. Department of Education, 2003; Walker \& Arbreton, 2005). We found that common reasons why youth reported not attending 
were other interests/activities and family obligations, such as caring for siblings. The reality is that competing demands on youths' time and family constraints make it difficult for some youth to attend on a consistent basis. Programs will have a greater likelihood of attracting youth and encouraging consistent involvement if they acknowledge these barriers to involvement and provide opportunities that young people would not otherwise have access to in their homes, schools, or neighborhoods (Anderson-Butcher, 2005).

The second goal of our study was to examine youths' perceptions of staff, peers, activities, and the extent to which clubs are organized in a way to support the needs for relatedness, competence, and autonomy. Hirsch (2005) describes the importance of adult mentors in helping youth feel like these organizations are a second home. In this sample, youth had both positive and negative impressions of the staff. As Hirsch described, many youth in this sample felt that they had developed supportive and trusting relationships with adults in these settings. On the other hand, some individuals had less favorable impressions of the adults. Developing supportive relationships with adults has been associated with continued participation in community-based organizations (Walker \& Arbreton, 2004). However, our findings illustrate variations in staff's ability to form relationships and connect with youth. The quality of the relationships appeared to be more dependent on the staffs' level of experience than the amount of time the youth had attended club. This was likely exacerbated by staff turnover, especially at one of the clubs where they went through three site directors over the course of year. Hiring practices may help to improve youths' experience with staff. Community-based programs should attempt to hire a diverse staff that reflects the demographic of youth served and can demonstrate that they understand and are responsive to young peoples' developing needs. One possibility for creating stronger relationships is to include adults in the program who already have a connection with the youth (e.g., teachers, coaches, and family member). Finally, ongoing training of staff that focuses on how to develop respectful, caring, and trusting relationships can help to improve youths' experiences.

Consistent with prior research, we found that the club was also an important setting for both developing and maintaining friendships (Hirsch, 2005; Loder \& Hirsch, 2003). Most youth enjoyed spending time with their friends at the club and talked about how their peers provided academic support, emotional support, and helped them to avoid negative behaviors. Our findings along with prior literature indicate that peers play a critical role in both attracting youth to clubs and keeping them coming back (Hirsch, 2005; Lauver \& Little, 2005). Practitioners should provide opportunities for youth to socialize and hang out with a diverse group of peers in both structured and unstructured activities. They should also provide multiple opportunities for team building, cooperative learning, and working together on a project to develop a sense of community. One concerning finding was the bullying that some youth talked about occurring at one of the middle school clubs. Negative peer dynamics is an issue that should be taken seriously be program staff. Promoting a strong peer climate that emphasizes the inclusion of all members and maintains expectations for socially appropriate behavior is important for both recruitment and retention efforts.

In addition to the social environment, our findings suggest that it is important to consider both the diversity and the types of activities offered in these settings. In general, youth reported that they enjoyed the activities and had fun at the clubs, though they were not necessarily challenged in these settings. To increase the 
probability that youth will demonstrate competence, staff should offer a diversity of activities in areas that are developmentally appropriate, meaningful, and interesting to youth. Moreover, staff should work to design activities that encourage youth to learn new skills that have appropriate levels of challenge. One concern expressed by some youth was the amount of time spent on academics and the inflexibility in scheduling. The new demands for accountability had raised concerns about after-school programs becoming an extension of the school day and losing some of their youth development focus (Hirsch, 2005). There are important questions about the amount of time and best ways to incorporate academic activities into after-school programs. One possibility is that rather than always having a separate time for homework, there may be ways to integrate academics into other activities or use a more structured homework preparation program. In addition, greater flexibility in terms of scheduling and type of activities may help to improve youths' experience. Finally, staff should make sure that there is a range of books and other activities available for youth who finish their homework before the allotted time.

Finally, our findings suggest that the clubs are settings where youth experience some degree of choice, though the opportunities for autonomy were greater at middle school level than the elementary school level. Youth who attended the clubs had some say in the activities that were offered and had opportunities to make choices about how to spend time in both structured and unstructured activities. McLaughlin's (2000) research on high-quality community organizations suggests additional ways programs can encourage autonomy by providing them with opportunities to serve as leaders and develop responsibility.

It was interesting to note that we documented more similarities than differences in elementary and middle school youths' perception of staff, peers, and activities. Eccles (2005) has argued that one reason why youth may drop out of organized activities "is the failure of these programs to provide the kind of roles that adolescents might find challenging and respectful of their increasing maturity and expertise" (p. 357). Although middle school youth discussed more opportunities for autonomy, there were few other differences in their perceptions of the activities and relationships with adults and peers. Practitioners can increase participation in early adolescence in the following ways: (a) develop challenging tasks that offer opportunities to learn life, educational, and vocational skills; (b) offer a variety of skill-building activities that are both interesting and meaningful to this age group; (c) involve youth in decision making about program planning and activities; (d) provide opportunities to both help and serve others in the community; and (e) work to create a context where youth have opportunities to experience a sense of belonging and form warm and supportive relationships with both adults and peers.

Our findings also suggest important directions for future inquiry. We chose to interview elementary and middle school youth who varied in their duration and frequency of involvement about why they initially came, why they chose to come, and their perceptions of context. To truly understand why youth dropout of organized activities, we need to interview youth who no longer attend these programs about their motivation and both perceived and experienced barriers to involvement. In future studies, it will be important to follow youth attending these programs over time and compare them on academic and social outcomes to a group of youth drawn from the same community who chose not to attend BGCAs. In addition, we choose to interview youth in typical school-based BGCAS, which has implications for the generalizability of our findings. An interesting question for future work is how youths' motivation and 
experience are shaped by the location of the program (i.e., school versus community center). Another important area of work is intensive observational studies that describe youths' experiences in these settings and how and why certain aspects of the context effect motivation, participation, and engagement. Our study also raises several questions about using self-determination theory to understand motivation and participation in out-of-school settings. For example, one question that arises from this work is whether involvement is higher in programs that are organized in a way to support the need for relatedness, autonomy, and competence. Another important question is whether middle school programs that are organized in a way to support the changing needs of early adolescence are better able to both attract and retain middle school youth.

\section{REFERENGES}

Aberton, A., Sheldon, J., \& Herrera, C. (2005). Boys and Girls Club: A synthesis of 20 years of research on the Boys and Girls Club. Philadelphia, PA: Public Private Ventures.

Anderson-Butcher, D. (2005). Recruitment and retention in youth development programming. The Prevention Researcher, 12, 3-6.

Anderson-Butcher, D., Newsome, W., \& Ferrari, T. (2003). Participation in Boys and Girls Clubs and relationships to youth outcomes. Journal of Community Psychology, 31, 39-55.

Borden, L., Perkins, D., Villarruel, F., \& Stone, M. (2005). To participate or not participate: That is the question. New Directions for Youth Development, 105, 33-48.

Brustad, R.J., Babkes, M.L., \& Smith, A.L. (2001). Youth in sport: Psychological considerations. In R. Singer, H. Hausenblas, \& C. Janelle (Eds.), Handbook of sport psychology (pp. 604-636). New York: Wiley.

Carruthers, C.P., \& Busser, J.A. (2000). A qualitative outcome study of Boys and Girls Club program leaders, club members, and parents. Journal of Park and Recreation Administration, $18,50-67$.

Catalano, R.F., Beglund, M.L., Ryan, J.A., Loncza, H.S., \& Hawkins, J.D. (1999). Positive youth development in the United States: Research findings on evaluations of positive youth development programs. Seattle, Washington: Social Development Research Group, University of Washington, School of Social Work.

Eccles, J.S. (2005). The present and future of research on activity settings as developmental contexts. In J.L. Mahoney, R.W. Larson, \& J.S. Eccles (Eds.), Organized activities as contexts of development: Extracurricular activities, after-school and community programs (pp. 353-372). Mahwah, NJ: Lawrence Erlbaum Associates.

Eccles, J.S., \& Gootman, J.A. (Eds.). (2002). Community programs to promote youth development. Washington, DC: National Academy Press.

Eccles, J.S., Midgley, C., Wigfield, A., Buchanan, C.M., Reuman, D., Flanagan, C., et al. (1993). Development during adolescence: The impact of stage-environment fit on young adolescents' experience in school and in families. American Psychologist, 48, 90-101.

Feldman, A.F., \& Matjasko, J.L. (2005). The role of school-based extracurricular activities in adolescent development: A comprehensive review and future directions. Review of Educational Research, 75, 159-210.

Fletcher, A.C., Elder, G.H., \& Mekos, D. (2000). Parental influences on adolescent involvement in community activities. Journal of Research on Adolescence, 10, 29-48.

Fredricks, J.A., Alfeld-Liro, C., Eccles, J.S., Hruda, L.Z., Patrick, H., \& Ryan, A.M. (2002). A qualitative exploration of adolescents' commitment to athletics and the arts. Journal of Adolescent Research, 17, 68-97. 
Fredricks, J.A., \& Eccles, J.S. (2004). Parental influences on youth involvement in sports. In M. Weiss (Ed.), Developmental sport and exercise psychology: A lifespan perspective (pp. 145-164). Morgantown, WV: Fitness Information Technology.

Guavain, M., \& Perez, S.M. (2005). Parent-child participation in planning children's activities outside of school in European American and Latino families. Child Development, 76, 371-383.

Gephart, M.A. (1997). Neighborhoods and communities as contexts for development. In J. Brooks-Gunn, G.J. Duncan, \& J.L. Aber (Eds.), Neighborhood poverty (Vol. 1): Contexts and consequences for children (pp. 1-43). New York: Russell Sage Foundation.

Halpern, R. (1999). After-school programs for low-income children: Promise and challenge. Future of Children: When School is Out, 9, 81-95.

Halpern, R., Barker, G., \& Mollard, W. (2000). Youth programs as alternative spaces to be: A study of neighborhood youth programs in Chicago's west town. Youth and Society, 21, $469-506$.

Hirsch, B. (2005). A place called home: After-school programs for urban youth. New York: Teachers College Press.

Hirsch, B.J., Roffman, J., Deutsch, N., Flynn, C., Loder, T., \& Pagano, M. (2000). Inner city youth development organizations: Strengthening programs for adolescent girls. Journal of Early Adolescence, 20, 210-230.

Huebner, A.J., \& Mancini, J.A. (2003). Shaping structured out-of-school time use among youth: The effects of self, family, and friends. Journal of Youth and Adolescence, 32, 453-463.

Hultzman, W. (1993). The influence of others as barrier to recreation participation among early adolescents. Journal of Leisure Research, 25, 150-164.

Loder, T.L., \& Hirsch, B.J. (2003). Inner-city youth development organizations: The salience of peer ties among early adolescent girls. Applied Developmental Science, 7, 2-12.

Mahoney, J.L., Larson, R.W., \& Eccles, J.S. (Eds.). (2005). Organized activities as contexts of development: Extracurricular activities, after-school, and community programs. New Jersey: Lawrence Erlbaum Associates.

Marzke, C., Hidreth, J., \& Smith, D. (2001). Evaluation of the Boys and Girls Clubs of America career preparation pilot program. Washington, DC: Public Policy Associates.

McLaughlin. (1999). Community counts: How youth organizations matter for youth development. Washington, CD: Public Education Network.

NVivo Software. (2008). QSR International: Victoria, Australia.

Lauver, S.C., \& Little, M.D. (2005). Recruitment and retention strategies for out-of-school-time programs. New Directions for Youth Development, 105, 71-89.

Loder, T., \& Hirsch, B.J. (2003). Inner-city youth development organizations: The salience of peer times among early adolescents. Applied Developmental Science, 7, 2-12.

Patrick, H., Ryan, A.M., Alfeld-Liro, C., Fredricks, J.A., Hruda, L.Z., \& Eccles, J.S. (1999). Adolescents' commitment to developing talent: The role of peers in continuing motivation for sports and the arts. Journal of Youth and Adolescence, 28, 741-763.

Perkins, D.F., Borden, L.M., Villarruel, F.A., Carlton-Hugh, A., Stone, M.R., \& Keith, J.G. (2007). Participation in structured youth programs: Why ethnic minority youth choose to participate or not participate. Youth and Society, 38, 420-442.

Roffman, J.G., Pagano, M.E., \& Hirsch, B.J. (2001). Youth functioning and experiences in innercity after-school programs among age, gender, and race groups. Journal of Child and Family Studies, 10, 85-100.

Ryan, R.M., \& Deci, E.L. (2000). Self-determination theory and the facilitation of intrinsic motivation, social development, and well-being. American Psychologist, 55, 68-78.

Schinke, C., Orlandi, M., \& Cole, C. (1992). Boys and Girls Clubs in public housing developments: Prevention programs for youth at risk. Journal of Community Psychology, 118-128. 
St. Pierre, T.L., Mark, M.D., Kaltreider, L., \& Aikin, K.J. (1997). Involving parents of high risk youth in drug prevention: A Three year longitudinal study of Boys and Girls Clubs. Journal of Early Adolescence, 17, 21-50.

U.S. Department of Education, Department of the Under Secretary. (2003). When schools stay open late: The national evaluation of the 21 st century community learning programs: First year findings. Washington, DC: Author.

Vandell, D.L., Reisner, E.R., Brown, B.B., Pierce, K.M., Dadisman, K., \& Pechman, E.M. (2004). The study of promising after-school programs: Descriptive report of the promising programs. Washington, DC: Policy Studies Associates.

Walker, K.E., \& Arbreton, A.J.A. (2004). After-school pursuits: An examination of outcomes in the San Francisco Beacon Initiative. San Francisco: Public Private Ventures. Available at: www.ppv.org/ppv/publications/assets/168_publication.pdf

Weiss, H.B., Little, P.M.D., \& Bouffard, S.M. (2005). (Eds.). New directions in youth development: Vol. 105. Participation in youth programs: Enrollment, attendance, and engagement. San Francisco: Jossey-Bass.

Weiss, M.R., \& Petlichkoff, L.M. (1989). Children's motivation for participation in and withdrawal from sport: Identifying the missing links. Pediatric Exercise Science, 1, 195-211.

Weiss, M.R., \& Williams, L. (2004). The why of youth sport involvement: A developmental perspective on motivational processes. In M. Weiss (Ed.), Developmental sport and exercise psychology: A lifespan perspective (pp. 223-268). Morgantown, WV: Fitness Information Technology. 